\title{
Rodent Models of Diabetes and Diabetes Complications
}

\author{
Eleazar Shafrir ${ }^{1}$ and Yasunori Kanazawa ${ }^{*}, 2$ \\ ${ }^{I}$ Hadassah University Hospital and Hebrew University-Hadassah Medical School, Jerusalem 91120, Israel \\ ${ }^{2}$ Japanese Diabetes Foundation, Tokyo, Japan
}

\begin{abstract}
The rats listed here have been extensively studied as animal models of diabetic complications and their pathogenesis. The results of studies with the SHROB, JCR:LAcp and OLETF rats are instructive in understanding macro vascular diseases. The Cohen, GK, SHROB and OLETF rats are model of diabetic kidney disease. The SHROB rat might also be useful for diabetic retinopathy study. The importance of mitochondrial inactivity in diabetes was demonstrated with the ZDF rat. The heterogeneous complication models may be useful to understand pathogenesis, prevention and treatment of complications of diabetes mellitus.
\end{abstract}

Keywords: Macro vascular complication, nephropathy, retinopathy, mitochondrial diabetes.

\section{INTRODUCTION}

Animal models of diabetes that have been described in several recent publications [1-3] mainly have addressed the mechanisms of changes leading to development of diabetes and their genetic derivation. However, another aspect that seems important and requires special research is the evolution of diabetes complications in different species, the molecular basis of their induction, and possible arrest and prevention. We describe and discuss the extensively studied rodent models with spontaneous or nutritional induction of the disease rather than the transgenic or knockout models of diabetes.

\section{SHROB (KOLETZKY) RAT}

The spontaneously hypertensive and obese rat that evolved from the SHR obese rat lines [4] has many primary and secondary characteristics of the human metabolic syndrome as a nonsense mutation affecting all forms of the leptin receptor, designated $f a^{k}$, i.e., hyperphagia, enhanced lipogenesis, extensive growth of adipose tissue, impaired glucose tolerance without overt hyperglycemia, marked hyperinsulinemia with insulin hypersecretion from enlarged islets, insulin resistance, reduced expression of insulin receptor (IR) and insulin receptor substrate (IRS) protein, and a defective insulin signaling pathway.

Since the SHROB rat is not hyperglycemic, the complications in this animal cannot be directly linked to glucose hyperoxidation. Glomerulopathy with proteinuria occur involving focal segmental nephrosclerosis and hypertensive vascular lesions most probably due to overactivity of the renin-angiotensin system.

Atherosclerosis is related to impaired clearance of circulating leptin due to absence of the functional leptin receptor. Retinal neurovascularization, progressive capillary

*Address correspondence to this author at the Japanese Diabetes Foundation, Tokyo, Japan; Tel: +81-03-3815-2050; Fax: +81-03-38154954; E-mail: Ykanazawa@aol.com dropout, and vascular abnormalities and retinal hemorrhage are also evident.

\section{JCR:LACP RAT}

The JCR:LAcp rat [5], inbred from the corpulent hyperphagic rat $c p$ strains, also presents when young with most of the manifestations of the metabolic syndrome with particular micro- and macrovascular lesions. The animal has insulin resistance, hyperinsulinemia without loss of hypersecretion capacity, hyperlipidemia including both cholesterol and triglycerides, vasculopathy, atherosclerosis, and a unique cardiovascular disease with cardiac ischemia that calls for a cardioprotective pharmacologic agent. The rats slowly progress to full-blown type 2 diabetes. The origin of the lesions is polygenic and related to the unknown components of the genome derived from corpulent rat strains.

Among the complications are vasculopathy, atherosclerosis with thrombi linked to the arterial surface, intimal lesions in the vascular smooth muscle cells, and glomerular sclerosis and impaired wound healing.

\section{ZUCKER DIABETIC FATTY (ZDF) RAT}

Several diabetic males and females were identified in the obese Zucker $f a / f a$ colony and selectively inbred. After 10 generations the ZDF trait was established [6]. The rats are hyperglycemic and hyperinsulinemic until total failure of the beta cells associated with reduction of islet mitochondrial enzymes. The animals are also mildly hypertensive and hyperlipidemic. Two mutations of the leptin receptor reduce its affinity for interaction with leptin and are responsible for ZDF obesity.

The rise in triglyceride-rich lipoproteins appears to be correlated with the change from the hyperinsulinemic to the insulinopenic stage. Decrease in endothelial-dependent vasodilation and resting blood flow have been observed, indicating disrupted endothelial regulation. Ocular changes include retinal hypercellularity and a thick capillary basement membrane. Reduced wound healing and nerve conduction velocity with nerve edema have been reported. 


\section{COHEN DIABETIC RAT}

A.M. Cohen in Jerusalem developed the Cohen diabetic rat [7], a model of nutritionally induced type 2 diabetes. A diabetogenic diet rich in sucrose and poor in copper was fed to the "Sabra" albino rat strain of the Hebrew University with two contrasting results. A sensitive group developed full-blown type 2 diabetes, whereas a resistant group did not become hyperglycemic. The sensitive group developed beta cell dysfunction and reduced insulin secretion with insulin reistance. The hyperglycemia was reversible with dietary adjustment.

The chief complications were nephropathy with mesangial expansion and thickening of the glomerular basement membrane, proliferative retinopathy, testicular atrophy and gastrointestinal disorders, skeletal pathology, amd embryopathy.

\section{GOTO KAKIZAKI (GK) RAT}

The GK rat [8] is a nonobese substrain of Wistar origin that develops type 2 diabetes due to impaired beta cell mass function and glucotoxicity stemming from polygenic inheritance. Y. Goto and coworkers in Sendai, Japan, developed the GK rat by repeated selection and breeding of animals with reduced glucose tolerance chosen from a large pool of rats over several generations. The diabetes in the chosen, isolated rats was reproducible even after more than 100 generations. The primary defect was in the beta cells with "starfish-shaped" abnormalities but with somewhat differing phenotypical properties in the substrain colonies maintained by various investigators.

Among the complications investigated in the GK rats were nephropathy with thickening of the glomerular basement membrane, reduced nerve conduction velocity and segmental demyelinization, osteopathy, and altered retinal endothelial retinopathy and cell/pericyte ratio.

\section{OLETF RATS}

K. Kawano and associates in Tokushima, Japan, developed three diabetes models by selective breeding in a group of LongEvans rats obtained from Charles River Co. in Canada [9]. These models are a line of type 2 diabetic rats referred to as OLETF (Otsuka Long-Evans Tokushima Fatty) that are hyperphagic and consume up to 30 grams of food daily, a line referred to as LETL (Long-Evans Tokushima Lean) resembling type 1 insulin-dependent diabetes, and a line referred to as LETO (Long-Evans Tokushima) non-diabetic control rats. The OLETF rats exhibit glucose intolerance and insulin resistance, hypertriglyceridemia with marked triglyceride infiltration into the pancreatic islets, obesity, and increased blood pressure. The onset of diabetes and complications was significantly attenuated by diet restriction.

The outstanding complication was nephropathy with proteinuria. Glomerular oxidative lesions were evident similar to those in human nephropathy, fibrin-cap, capsular drop, and aneurysmal dilatation of the intraglomerular vessels.

\section{PSAMMOMYS OBESUS GERBIL}

Psammomys obesus (previously referred to as "sand rat") is a gerbil living in the desert or semidesert areas of North Africa and the Near East [10]. The gerbil is not hyperphagic or diabetic in the wild, but it is poorly adapted to nutritional excess. In the laboratory, the animal becomes hyperinsulinemic and hyperglycemic with marked insulin resistance when its native diet of salt bush (Atriplex halimus) is replaced by a laboratory rodent diet. After a few weeks on the laboratory diet, the animals develop insulin resistance with hyperinsulinemia, then gradually lose their pancreatic beta cells and their insulin levels markedly decrease. It is noteworthy that their insulin resistance is related to the inhibition of IR action, a shift in the tyrosine to serine phosphorylation on IRS and blockage of insulin signaling. Insulin resistance and the change in the phosphorylation pattern is related to increased activity of an enzyme of the protein kinase isoenzyme group protein kinase $\mathrm{C}$ epsilon $(\mathrm{PKC} \varepsilon)$, which inhibits tyrosine phosphorylase. The intraperitoneal injection of a peptide removed from the catalytic region of PKC abrogated the inhibitory serine phosphorylation of IRS by PKCE and enabled functioning of the downstream insulin signaling [11]. Psammomys is a good model for the study of insulin signaling pathway in muscles.

Most diabetes complications of Psammomys are related to insulin resistance and hyperglycemia. Cataracts are often evident and retinal lesions also occur. Among other complications, angiopathy, degeneration of intervertebral discs, spondylitis, hearing impairment, and nephropathy due to Na-K ATPase hyperactivity have been reported.

\section{SPONTANEOUSLY DIABETIC TORII (SDT) RAT}

The Spontaneously Diabetic Torii (SDT) rat [12], a spontaneous animal model of non-obese type 2 diabetes resembling that in humans, was established in 1997. A cumulative incidence of diabetes of $100 \%$ was noted by 40 weeks of age in male rats, while it was only 33\% even by 65 weeks of age in female rats. The male SDT rats were hyperglycemia and hypoinsulinemic from 25 weeks of age; had a significant increase in urea nitrogen levels, urinary protein excretion, and HbA1c levels from 35 weeks of age; and survived over the long term without insulin treatment after onset of diabetes. In addition, obesity did not develop in the male or female rats. The most characteristic features of the SDT rat are the diabetic ocular complications, i.e., cataract, diabetic retinopathy (DR), and neovascular glaucoma. The cataract develops to maturity, and the DR becomes advanced. Although the SDT rat is noteworthy for its diabetic ocular complications, other diabetic complications may develop in this rat. The details of the other diabetic complications are discussed in this special issue.

\section{CONCLUDING OPINION}

There is no need to underscore the huge contribution of animal models to the investigations of the causes of diabetes. However, much research remains to be performed on the road to understanding and preventing the complications of this disease, particularly the development of diabetic tissue lesions. This is of immeasurable importance to the amelioration and prevention of human diabetes and promotion of pharmacologic approaches to combat diabetes.

\section{REFERENCES}

[1] Shafrir E. Animal models of diabetes, frontiers of research. Boca Raton (FL): CRC Press 2007. 
[2] Shafrir E, Ziv E. A useful list of spontaneously arising animal models of obesity and diabetes. Am J Physiol Endocrinol Metab 2009: E1451-2.

[3] Shafrir E. Diabetes in animals: Contribution to the understanding of diabetes by study of its etiopathology in animal models. In: Porte D Jr., Sherwin RS, Baron A, Eds. Diabetes Mellitus Textbook. 6th ed. New York: McGraw-Hill 2003; pp. 231-56.

[4] Koletzky RJ, Veliquette RA, Ernsberger P. The SHROB (Koletzky) rat as a model for metabolic syndrome. In: Shafrir E, Ed. Animal models of diabetes, Frontiers in Research, Boca Raton, FL: CRC Press 2007; pp. 185-207.

[5] Russel JC, Kelly SE, Proctor S. The JCR: LA-cp rat: animal model of the metabolic syndrome exhibiting micro- and macromolecular disease. In: Shafrir E, Ed. Animal models of diabetes, Frontiers in Research. Boca Raton (FL): CRC Press 2007; pp. 159-83.

[6] Peterson RG. The Zucker Diabetic Fatty (ZDF) rat. In: Sima AAF, Shafrir E, Eds. Animal Models of Diabetes. A Primer. In: The Netherlands: Harwood Academic Publishers 2001; pp. 109-28.

[7] Wechsler-Zangen S, Orlanski E, Zangen DH. Cohen diabetic rat. In: Shafrir E, Ed. Animal models of diabetes. Frontiers in Research. Boca Raton (FL): CRC Press 2007; pp. 323-34.
[8] Ostenson CG. The Goto-Kakizaki rat. In: Shafrir E, Ed. Animal models of diabetes. Frontiers in Research. Boca Raton (FL): CRC Press 2007; pp. 119-37.

[9] Kawano K. OLETF rats: model for the metabolic syndrome and diabetic nephropathy in humans. In: Shafrir E, Ed. Animal models of diabetes. Frontiers in Research. Boca Raton (FL): CRC Press 2007; pp. 209-22.

[10] Ziv E, Kalman R, Shafrir E. Psammomys obesus: nutritionally induced insulin resistance, diabetes and beta cell loss. In: Shafrir E, Ed. Animal models of diabetes. Frontiers in Research. Boca Raton (FL): CRC Press 2007; pp. 289-310.

[11] Mack E, Ziv E, Reuveni H, et al. Prevention of insulin resistance and beta-cell loss by abrogating PKCepsilon-induced serine phosphorylation of muscle IRS-1 in Psammomys obesus. Diabetes Metab Res Rev 2008; 24: 577-84.

[12] Shinohara M, Masuyama T, Kakehashi A. The Spontaneously Diabetic Torii (SDT) Rat with retinopathy lesins resembling those of humans. In: Shafrir E, Ed. Animal models of diabetes, Frontiers in Research. Boca Raton (FL): CRC Press 2007; pp. 311-21.

Received: May 19, 2010

Revised: December 8, 2010

Accepted: January 15, 2011

(C) Shafrir and Kanazawa; Licensee Bentham Open.

This is an open access article licensed under the terms of the Creative Commons Attribution Non-Commercial License (http://creativecommons.org/licenses/by-nc/3.0/) which permits unrestricted, non-commercial use, distribution and reproduction in any medium, provided the work is properly cited. 